\title{
Coronelismo, Guerra Civil Federalista e Contestado: Breve Análise das Relações Políticas no Paraná
}

\author{
Cássio Alexandre de Souza ${ }^{1}$
}

- Enviado em 29/10/2016

- Aprovado em 15/11/2016

No contexto histórico político, ao longo dos meses em que esteve na iminência da Guerra Civil Federalista (1893-1894), o Paraná estava dividido entre liberais, simpatizantes do império que apoiaram os federalistas e republicanos florianistas, que pretendiam consolidar a República do Marechal Floriano Peixoto com a derrota dos maragatos. Em 1892, o Dr. Francisco Xavier da Silva (1838-1922) foi eleito Presidente do Estado do Paraná, sendo o Dr. Vicente Machado da Silva Lima eleito como Vice-Presidente. Em agosto de 1893, por ocasião do licenciamento do Dr. Francisco Xavier da Silva, Vicente Machado assumiu a Presidência do Estado. No decorrer do avanço dos federalistas em Santa Catarina e a consequente invasão do território paranaense, o Dr. Vicente Machado² protagonizou uma questionável contradição: No início de janeiro de 1894, lançou um manifesto aos cidadãos curitibanos, assegurando que a Guarda Nacional e as forças do Regimento de Segurança do Paraná combateriam os maragatos a todo custo, e alguns dias depois, em 16 de janeiro, fugiu junto do General Antônio José Maria Pêgo Júnior (que havia sido designado pelo Marechal Floriano para comandar e guarnecer o Distrito Militar do Paraná) e de sua comitiva para a

\footnotetext{
1 Bacharel e Licenciado em História pela Universidade do Contestado (2014), Campus Mafra - Santa Catarina. Pós-graduado em Política e Sociedade (Universidade do Contestado), 2016. Associado Correspondente do IHGPR. E-mail: cassio.olsen.souza@gmail.com

${ }^{2}$ Vicente Machado da Silva Lima (Castro, 1860 - Curitiba, 1907) foi um magistrado e político paranaense. Em São Paulo, bacharelou-se em Direito pela Faculdade do Largo de São Francisco, em 1881. Regresso ao Paraná foi nomeado Promotor Público, Secretário do Governo Provincial (no governo do Dr. Carlos de Carvalho), Juiz Municipal de Órfãos de Ponta Grossa e Professor de Filosofia do Ginásio Paranaense. Nos biênios de 1886-1887 e 1888-1889, foi eleito Deputado Provincial pelo Partido Liberal. Com a Proclamação da República, fundou no Paraná o Diretório do Partido Republicano Paranaense. Em 1895 foi eleito Senador da República, e em 1904, Presidente do Estado do Paraná.
} 
cidade de Castro, ocasião em que decretou provisoriamente a transferência da capital do Estado também para Castro. Com o avanço das tropas federalistas no Paraná e a intensificação dos combates, em 18 de janeiro o Dr. Vicente Machado e sua família fugiram novamente, desta vez de Castro para São Paulo, voltando somente em maio de 1894, quando as forças federalistas já haviam sido expulsas do Paraná, sendo restabelecida a ordem republicana. Segundo Rafael Augustus Sêga:

A fuga de Vicente Machado de Curitiba para Castro deixou a capital a mercê da sanha dos revolucionários e, no dia 20, Curitiba era ocupada militarmente por uma força de 450 homens, sob o comando do chefe federalista Menezes Dória, aclamado governador provisório do Estado do Paraná para suceder Teófilo Soares Gomes (que havia sido empossado provisoriamente em Paranaguá dias antes). (SÊGA, 2008, p. 181).

Em Curitiba, entre os meses de fevereiro a abril de 1894, notáveis políticos envolveram-se com os acontecimentos da Guerra Civil no Paraná: O Barão do Serro Azul3, como reconhecido representante político dos cidadãos curitibanos, organizou uma Junta de Governo Provisório composta de membros da Câmara Comercial de Curitiba, arrecadando recursos para custear os dois Empréstimos de Guerra concedidos a Gumercindo Saraiva, sendo pagos em contos de réis para que poupassem a capital de violências, saques e abusos. Em maio de 1894, o trágico acontecimento do Km 65 da ferrovia da Serra do Mar, onde foi fuzilado o Barão do Serro Azul junto de outros integrantes da comissão que concedeu o empréstimo de guerra, deixou suspeitas de que a trama se deu pelo oportuno momento de parcialidade política, em meio à suspensão das garantias constitucionais e a aplicação in continenti da pena de fuzilamento, por razão de que não houve por parte da Junta Comercial de Curitiba a intenção de subsidiar o movimento dos federalistas, ao contrário do que acusavam os florianistas republicanos, mas sim de poupar suas vidas e (ao menos alguns de) seus bens, em face ao momento fatídico que enfrentavam, conforme Valério Hoerner Júnior:

\footnotetext{
${ }^{3}$ Ildefonso Pereira Correia (Paranaguá, 1845 - Serra do Mar, 1894), o Barão do Serro Azul (nomeado por decreto imperial de 1888), foi um empresário da Erva-Mate e político paranaense. Ilustre e abastado fazendeiro de Curitiba, foi Deputado Provincial e Intendente de Curitiba por ocasião da invasão federalista pelas tropas de Gumercindo Saraiva. Após a Guerra Civil, foi fuzilado sumariamente no Km 65 da estrada de ferro da Serra do Mar (que liga Curitiba a Paranaguá), em maio de 1894, considerado traidor da República pelo Marechal Floriano Peixoto (cf. Túlio Vargas, in A Última Viagem do Barão do Serro Azul).
} 
Esses títulos comprobatórios dos empréstimos, ocorridos em duas fases, nada mais representaram do que um simples negócio, caracterizado pela escolha entre pagar e ser impiedosamente saqueado, nesse caso, a cidade inteira. Diante desse risco, o Barão optou por pagar, especialmente porque seria também, grande proprietário que era, um dos saqueados. Em momento algum, porém, Serro Azul estabeleceu maiores vínculos com os revolucionários. A ordem vinda do Marechal Floriano, talvez como resposta a uma indagação feita pelo indeciso General Ewerton Quadros - que faço? Estava diretamente ligada ao conteúdo da conversa que tivera no mês de janeiro com o Vice-Governador Vicente Machado, que o prevenira estar Curitiba nas mãos de um monarquista, homem rico e de muito prestígio [...]. (JÚNIOR, 2010, p. 79-80).

Após os atos diplomáticos do Barão do Serro Azul, o médico e político Dr. João Menezes Dória (1857-1934) foi nomeado para governar provisoriamente o Paraná, cuja sede estava estabelecida em Curitiba. Junto do Dr. Menezes Dória estava o Dr. Generoso Marques ${ }^{4}$ que havia sido Presidente do Paraná entre 3 de junho a 29 de novembro de 1891, sendo deposto por decreto do Marechal Floriano Peixoto, no momento em que este assumiu a Presidência da República, por ocasião da renúncia do Marechal Deodoro da Fonseca. Oferecendo apoio ao movimento federalista no Paraná, o Dr. Generoso Marques juntamente com o Desembargador Emygdio Westphalen ${ }^{5}$ administraram a Junta Governativa Federalista, sediada na ilha do Desterro, em Santa Catarina, articulando o trâmite jurídico que lhes asseguraria a imunidade após o conflito, indiferentemente a parte que consolidasse seu governo, estando assim configurada a rede de poder federalista durante o período revolucionário nos Estados do Paraná e Santa Catarina:

Para governar o estado, os líderes federalistas nomearam o Dr. João Menezes Dória. Médico humanitário e popular, aliado de Generoso Marques, Dória combatera Vicente

\footnotetext{
${ }^{4}$ Generoso Marques dos Santos (Curitiba, 1844 - 1928) foi um advogado e político paranaense. Graduou-se em Direito pela Faculdade de Direito do Largo de São Francisco, em São Paulo, 1865. Foi Deputado e Senador da República. Ao assumir a presidência do Estado do Paraná, na eleição republicana, não conclui seu mandato por conta de sua deposição, decretada pelo Marechal Floriano ao assumir a Presidência da República. Ao final Guerra Civil Federalista, se exilou na Argentina, retornando ao Brasil após obter o Habeas Corpus impetrado por Ruy Barbosa, junto ao Supremo Tribunal Federal, em face de sua condição de imunidade como Senador, em 1897 (cf. Milton Miró Vernalha, op.cit.).

${ }^{5}$ Emygdio Westphalen (Lapa, 1847 - Curitiba, 1927), foi um desembargador, magistrado e político paranaense. Bacharelou-se em São Paulo, pela Faculdade de Direito do Largo de São Francisco, em 1867. Após atuar como Promotor Público no Rio de Janeiro retornou a Lapa, atuando como Promotor Público e depois Vereador. Em 1882 foi nomeado Juiz de Direito de Curitiba e da Comarca da Lapa, sendo eleito Deputado Provincial em 1886. Em 1891, no período de instalação do regime republicano constitucional, foi nomeado Desembargador do Tribunal do Estado do Paraná. Após a Guerra Civil Federalista, quando retornou do exílio na Argentina, exerceu o cargo de Procurador-Geral do Estado do Paraná (idem).
} 


\begin{abstract}
Machado, tendo sido preso e enviado ao Rio de Janeiro, de onde fugiu e retornou ao Paraná. De volta ao Estado, organizou uma coluna para apoiar as tropas de Gumercindo que sitiavam a Lapa. Para incensar a elite paranaense, os chefes "revolucionários" indicaram o lapeano Emygdio Westphalen para integrar o Governo Provisório Nacional, sediado no Desterro. (MOCELLIN, 2014, p. 117).
\end{abstract}

Ao ser restabelecida a ordem republicana no Paraná, em maio de 1894, iniciou-se um novo período da Guerra Civil, onde ao invés das batalhas entre maragatos e pica-paus, estrearam as perseguições políticas, prisões e fuzilamentos sumários. Ilustres idealistas paranaenses conheceriam intimamente o autoritarismo e a tirania de Floriano Peixoto e seus correligionários na violenta retaliação de quem venceu para quem foi derrotado na guerra. Nesse contexto, o Dr. Antônio Bley6 também foi vítima de perseguição política por conta de suas divergências com Vicente Machado. Tendo sido Juiz de Direito em várias comarcas do Paraná, protagonizou uma série de lides contra Vicente Machado (quando este atuou como Promotor Público e Advogado), sendo preso por delação falsa do mesmo, em maio de 1894, sob a acusação de ter contribuído com os esforços da invasão federalista no estado. Nesse sentido, o que ficou evidente ao longo da observação do contexto histórico-político do Paraná, bem como do Rio Grande do Sul e Santa Catarina, foi à acirrada e desleal disputa pelo poder político entre ilustres opostos das elites estaduais.

No Paraná, a indisposição entre os políticos e magistrados foi o cenário político que envolveu os combates armados nos campos de batalha, evidenciando o despreparo e respectivo autoritarismo para administrar questões contraditórias que geraram profundos embates na dimensão política dos recém-elevados Estados, por parte das elites dirigentes da política estadual, segundo Ricardo Costa de Oliveira:

Na República, continuaram dominando o poder econômico e o poder político nos âmbitos municipal, estadual e federal, como prefeitos, vereadores, deputados estaduais, deputados federais, senadores, altos burocratas nas diferentes esferas do aparelho de Estado. Monopolizaram a cúpula das Forças Armadas, as Academias de Direito e de Medicina, as instituições culturais, os jornais, os partidos políticos, as

\footnotetext{
${ }^{6}$ Antônio Bley (Rio Negro, 1850 - Castro, 1911), foi um Juiz de Direito do Paraná. Formou-se na Faculdade de Direito do Largo de São Francisco, em São Paulo, 1875. Filho de Nicolau Bley e Izabel Guebert Bley foi um notável magistrado, atuando em diversas comarcas do Paraná. Era reconhecido entre os juristas de sua época pela sua prudência e comprometimento ético com a Justiça. Perseguido e preso no período da Guerra Civil Federalista no Paraná provou no Tribunal a sua inocência, retornando a sua atuação como Juiz de Direito (cf. Waldemiro Bley Júnior, in Genealogia da Família Bley).
} 
eleições, os cargos públicos e de poder nas capitais estaduais e no Distrito Federal. No judiciário republicano continuaram sendo advogados, juízes e desembargadores influentes (OLIVEIRA, 2012, p. 59).

Não obstante os mecanismos jurídicos de punição e de cassação de direitos políticos, membros do Partido Republicano do Paraná mobilizaram forças para concretizar antigos planos de retaliações que já eram fomentados entre coronéis paranaenses há muitos anos antes da Guerra Civil Federalista, se aproveitando claramente do momento de parcialidade política e de suspensão dos direitos constitucionais por conta do descumprimento da legalidade. Essa disputa pelo poder político caracterizou os primeiros anos da República no Brasil, configurando as redes de poder estabelecidas pelas elites operadoras da burocracia das Câmaras, dos Fóruns, das Assembleias Estaduais, das Secretarias, dos Ministérios e do Congresso Federal. $\mathrm{O}$ fenômeno do Coronelismo esteve presente na Guerra Civil Federalista, e se destacou no contexto das causas das lutas aderidas ou renegadas pelos personagens que protagonizaram os conflitos, que sendo republicanos ou federalistas, tinham ao menos uma semelhança em comum: eram todos coronéis.

A relação entre o contexto do coronelismo, predominante no período da primeira República do Brasil (também chamada de República Velha, entre 1889 a 1930) e o conflito do Contestado, entre os anos de 1912 a 1916, caracteriza nitidamente a conjuntura política, econômica e social da região contestada entre os Estados de Santa Catarina e Paraná, litigada no então Supremo Tribunal Federal desde a última década do século XIX.

Além das questões relacionadas às elites políticas dos dois estados, que litigavam juridicamente por seus interesses privados, a disposição do território em questão era interessante aos coronéis catarinenses e paranaenses por conta da exploração da madeira nativa (florestas de Araucária e Imbuia), dos Ervais de Mate e dos terrenos demarcados pelo Governo Federal da República para a construção da ferrovia que ligaria o Estado de São Paulo ao Rio Grande do Sul, atravessando o território contestado entre Santa Catarina e Paraná. Dentre o expressivo empreendimento e o respectivo interesse das elites regionais, caracterizava-se na prática o modelo político do coronelismo, constituído do mandonismo concentrado na autoridade (formal ou informal) do coronel (ou, dos coronéis), segundo Edgard Carone: 
O fenômeno do coronelismo tem suas próprias leis e funciona na base da coerção da força e da lei oral, bem como de favores e obrigações. Esta interdependência é fundamental: o coronel é aquele que protege, socorre e sustenta materialmente os seus agregados; por sua vez, exige deles a obediência e a fidelidade. É por isso que o coronelismo significa força política e militar (CARONE, 1988, p. 66).

Nesse contexto, muitos coronéis envolveram-se diretamente nos acontecimentos que elencaram o conflito do Contestado, inclusive no Planalto Norte de Santa Catarina, onde também havia interesses de grandes latifundiários em negociar terras com os governos estadual e federal (para o repasse de concessões a Brazil Railway Company) e com a companhia americana da madeireira Lumber S.A., obtendo dessa forma lucros e vantagens políticas baseadas nas relações informais de compadrio entre os coronéis. Essas relações eram respectivamente convertidas em posses, poder político regional e dinheiro, muito dinheiro. 0 "espírito" do capitalismo, conforme diria Max Weber, estava intrínseco nas práticas dos coronéis, que baseavam muitas de suas convenções políticas nos lucros que poderiam ser obtidos em suas negociatas. Desse modo, as Câmaras municipais eram o palco da política regional, onde os protagonistas, sendo os coronéis ou seus agentes de interesses, negociavam entre si as pretensões econômicas, utilizando-se normalmente da via política, quando em tempos de certa diplomacia.

Instituída a liderança no município, alguns coronéis se projetaram a nível regional, passando também a disputar cargos eletivos e nominativos estaduais e até federais, normalmente na Câmara dos Deputados Federais ou no Senado, cujas intenções eram de subsidiar política e economicamente os interesses das elites estaduais. No caso dos municípios, ausentando-se o coronel, membros de sua confiança assumiam a posição de procuradores, tornando-se chefes locais tributários do chefe maior que se ausentou. (LEAL, 1997).

Quando não assumia pessoalmente os mandatos de vereador e prefeito sucessivamente, o coronel criava uma rede de poder, controlando o diretório do partido republicano, a atividade da câmara municipal e da divisão da Guarda Nacional, da qual era integrante com nomeação e posto, delegando poderes aos correligionários, bacharéis e 
funcionários públicos, alternando mandatos eletivos conforme os interesses de seu grupo, conforme descreve Leôncio Basbaum:

Em suas mãos estava toda a lei, a polícia, o escrivão, o juiz, os votos e as atas eleitorais feitas nos gabinetes. Desses gabinetes saíam os vereadores, os deputados, os presidentes e os senadores da República (BASBAUM, 1976, p. 147).

Em Rio Negro (no território correspondente atualmente ao município de Mafra, Santa Catarina), alguns coronéis também protagonizaram envolvimentos no conflito do Contestado, sobretudo na região entre Itaiópolis, Papanduva e São Lourenço. Dentre eles estava Aleixo Gonçalves de Lima, que junto com Antônio Tavares e Henrique Wolland, vulgo Alemãozinho, comandou o piquete de revoltosos que se instalou no interior entre Itaiópolis e Papanduva, terras de sua propriedade, que se estendiam da região entre Iracema até a Estiva. Fazendeiro e comerciante de certa notoriedade em Rio Negro, Aleixo Gonçalves era dissidente da elite política republicana instalada na Câmara de Rio Negro por conta de nunca ter ascendido com algum apoio aos cargos eleitorais da câmara. Assim sendo, envolveu-se no contestado ao lado de coronéis catarinenses que enfrentavam semelhante situação política.

Sua dissidência da elite rio-negrense que apoiava o Paraná na questão do território contestado já era conhecida, mesmo antes dos conflitos armados acontecerem. Em 1909, Aleixo Gonçalves liderou cerca de 500 homens no assalto ao Posto Fiscal do Paraná nas margens do Rio Preto, na divisa entre Rio Negro e Rio Negrinho, sendo aclamado pelos coronéis catarinenses, conforme menciona o Professor Antônio Dias Mafra:

\footnotetext{
Aleixo Gonçalves de Lima, Capitão da Guarda Nacional, Fazendeiro em Rio Negro e empresário do mate com interesses comerciais em São Bento, em setembro de 1909, segundo Vinhas de Queiroz (1981, p. 68), “capitaneando cerca de 500 homens e auxiliado pela polícia catarinense, transpôs o Rio Preto, e invadiu o território do Paraná, proclamando que visava impedir a cobrança dos impostos estaduais". [...] Aleixo foi aclamado como herói catarinense em Joinville porque afugentou os funcionários do Posto Fiscal paranaense e a força policial protetora. A sua atitude reflete o clima de animosidade entre catarinenses e paranaenses, que já havia se instalado na região. (QUEIROZ apud MAFRA, 2013, p. 161-162).
}

Em contrapartida dos revoltosos do Contestado, o coronel rio-negrense Nicolau Bley Netto, de família abastada e tradicional no município, foi um típico exemplo de coronel da 
República Velha. Herdou de seu pai, o Capitão João Bley (1840-1905), a tradição de atuação política na Câmara de Rio Negro, junto das fazendas e das casas de comércio que pertenciam à família. Ampliou seus negócios quando passou a investir no processamento de erva mate, sendo proprietário de ervais e engenhos no interior de Rio Negro, ao lado esquerdo do rio (atualmente Mafra, Santa Catarina). Durante os combates em Itaiópolis, Papanduva e Canoinhas, O Coronel Nicolau Bley Netto comandou uma força de destacamento da Guarda Nacional de Rio Negro, juntamente com o Coronel Júlio Sérgio Gomes da Silva, sob as ordens do General Setembrino de Carvalho, segundo Waldemiro Bley Júnior: "Na revolta do Contestado, mais uma vez ao lado do Governo, comandou uma coluna de 250 homens (os vaqueanos). Era na época Coronel Comandante da Guarda Nacional de Rio Negro". (JÚNIOR, 1987, p. 76).

Com o fim do conflito do Contestado, em 1916, e a respectiva sentença final da questão judicial entre Santa Catarina e Paraná, sendo lavrado o termo do Acórdão de divisas territoriais entre os estados, por decisão do Supremo Tribunal Federal, Nicolau Bley Netto foi nomeado pelo Governador do Estado de Santa Catarina, o Coronel Felipe Schmidt, para Presidente da Câmara Municipal do recém-criado município de Mafra, em setembro de 1917. Por sua vez, ao iniciar os trabalhos da Câmara Municipal, estabeleceu a Intendência Municipal (correspondente a uma Prefeitura subordinada a Câmara), e nomeou seu correligionário e também coronel ervateiro catarinense Victorino de Souza Bacellar, ao cargo de Intendente e depois Prefeito Municipal de Mafra, que administrou o município até a ocasião de seu falecimento, em 1922 (FORJAZ, 1929).

O coronel Nicolau Bley Netto também se elegeu Deputado Estadual em Santa Catarina

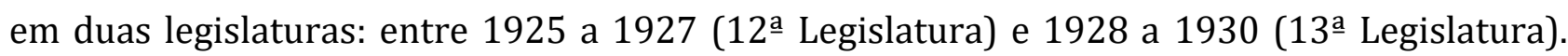
Exemplo de prestígio político e poder econômico entre os estados de Santa Catarina e Paraná, Nicolau Bley Netto foi um notável empreendedor político aos moldes do coronelismo característico dos indivíduos que compunham as elites políticas estaduais, sendo em muitos casos responsáveis por expropriações, fraudes eleitorais, notariais e abusos de poder político e coercitivo, elementos que tiveram grande influência nas causas que historicamente originaram a revolta do Contestado. Embora os ideais democráticos estivessem enraizados 
nos discursos liberais republicanos e federalistas da época, a experiência histórica deixa claro que no Brasil a República não foi sinônimo de democracia.

\section{REFERÊNCIAS}

BASBAUM, Leôncio. A História Sincera da República. 6ª Edição. São Paulo: Alfa-Ômega, 1976.

CARONE, Edgard. A Primeira República (1889-1930). Rio de Janeiro: Bertrand Brasil, 1988.

FORJAZ, Djalma. Centenário da Colonização Alemã em Rio Negro e Mafra (1829-1929). São Paulo: Empreza Editora Olivero, 1929.

JÚNIOR, Valério Hoerner. Maragatos: A Revolução Federalista no Paraná e o General Gumercindo Saraiva. Curitiba: Instituto Memória, 2010.

JÚNIOR, Waldemiro Bley. Genealogia da Família Bley. Curitiba: IHGPR, 1987.

LEAL, Victor Nunes. Coronelismo, Enxada e Voto. 0 Município e o Regime Representativo no Brasil. 3a Edição. Rio de Janeiro: Nova Fronteira, 1997.

MAFRA, Antônio Dias. 100 Anos da Guerra do Contestado: Desvendando a Participação de São Bento do Sul. Florianópolis: Nitram, 2013.

MOCELlin, Renato. Pica-Paus x Maragatos: A Mais Sangrenta Guerra Civil Brasileira. Curitiba: 2014.

OLIVEIRA, Ricardo Costa de. Na Teia do Nepotismo: Sociologia Política das Relações de Parentesco e Poder Político no Paraná e no Brasil. Curitiba: Insight, 2012.

QUEIROZ, Maurício Vinhas de. Messianismo e Conflito Social. São Paulo: Ática, 1981.

SÊGA, Rafael Augustus. Tempos Belicosos: A Revolução Federalista no Paraná. Curitiba: Instituto Memória, 2008.

VARGAS, Túlio. A Última Viagem do Barão do Serro Azul. Curitiba: Juruá, 2009.

VERNALHA, Milton Miró. Maragatos x Pica-Paus. Curitiba: Lítero-Técnica, 1984.

WEBER, Max. A Ética Protestante e o "Espírito" do Capitalismo. São Paulo: Companhia das Letras, 2014. 